\title{
Geo-environmental integration for sustainable development of water, energy, environment and society
}

\author{
M. Ouessar ${ }^{1}$ - B. Agoubi ${ }^{2}$ - C. King $^{3,4} \cdot$ R. N. Yadava ${ }^{5} \cdot$ K. Kocak $^{6}$ \\ Published online: 16 May 2020 \\ (C) Saudi Society for Geosciences 2020
}

Achieving the $17 \mathrm{UN}$ sustainable development goals (SDGs) and their 169 targets is a challenge, especially in regions where poverty and ecosystem degradation are major development constraints. Moreover, rapid economic growth and aspirations for higher living standards continue to put increasing pressure on natural resources, particularly in the context of climate change.

Integrated innovative approaches and methods, based on state-of-the-art scientific knowledge and technology advancement, can be of great help in meeting these challenges. These could be adopted by decision makers in order to ensure proper development while preserving the environment.

It is within this framework that this special issue of the Arabian Journal for Geosciences is dedicated to some of the latest developments in four main areas of SDGs: water, energy, environment and society. It encompasses a selection of 13 articles from more than 100 papers presented at two international conferences (ICWEES-2018 and IFWC-2018) held in Tunisia in 2018.

This article is part of the Topical Collection on Geo-environmental integration for sustainable development of water, energy, environment and society

M. Ouessar

Ouessar.Mohamed@ira.rnrt.tn

1 Institut des Régions Arides (IRA), University of Gabès, Médenine, Tunisia

2 Institut Supérieur des Sciences et Techniques des Eaux, University of Gabès, Gabès, Tunisia

3 University of Southampton, Southampton, UK

4 The Borders Institute (TBI), Nairobi, Kenya

5 Centre of Excellence in Water and Environmental Sciences, Rabindranath Tagore University (Formerly AISECT University), Bhopal, India

6 Faculty of Engineering \& Natural Sciences, Konya Technical University, Konya, Turkey
The main results are as follows:

- Geospatial tools and techniques (remote sensing and GIS) can help in smart land-use planning, land management and environmental monitoring.

- Hydrological modeling is a powerful tool for watershed management and mitigation of natural catastrophes.

- Conducting energy-water nexus analyses shows that harvesting freely available renewable energy is an affordable way to power water management solutions without increasing emissions.

- Crop water response modeling and water valuation could encourage substantial improvements in water use productivity.

Results from these studies could be widely used as geoscientific information-based insights for decision makers in elaborating local development plans and strategies. In this way they could achieve higher economic growth levels while making efficient use of natural resources. This would help to guarantee respectful social and environmental conditions for the populations. 